University of Nebraska - Lincoln

DigitalCommons@University of Nebraska - Lincoln

\title{
Comparison of the Trivalent Live Attenuated Vs. Inactivated Influenza Vaccines Among U.S. Military Service Members
}

Angelia A. Eick

Armed Forces Health Surveillance Center, U.S. Army Center for Health Promotion and Preventive Medicine, 2900 Linden Lane, Suite 200, Silver Spring, MD 20910, USA

Zhong Wang Armed Forces Health Surveillance Center, U.S. Army Center for Health Promotion and Preventive Medicine, 2900 Linden Lane, Suite 200, Silver Spring, MD 20910, USA

Hayley Hughes

Military Vaccine Agency, 5113 Leesburg Pike, Suite 402, Falls Church, VA 22041, USA

Stephen M. Ford

Military Vaccine Agency, 5113 Leesburg Pike, Suite 402, Falls Church, VA 22041, USA

Steven K. Tobler

Armed Forces Health Surveillance Center, U.S. Army Center for Health Promotion and Preventive Medicine, 2900 Linden Lane, Suite 200, Silver Spring, MD 20910, USA

Follow this and additional works at: https://digitalcommons.unl.edu/usarmyresearch

Part of the Operations Research, Systems Engineering and Industrial Engineering Commons

Eick, Angelia A.; Wang, Zhong; Hughes, Hayley; Ford, Stephen M.; and Tobler, Steven K., "Comparison of the Trivalent Live Attenuated Vs. Inactivated Influenza Vaccines Among U.S. Military Service Members" (2009). US Army Research. 7.

https://digitalcommons.unl.edu/usarmyresearch/7

This Article is brought to you for free and open access by the U.S. Department of Defense at DigitalCommons@University of Nebraska - Lincoln. It has been accepted for inclusion in US Army Research by an authorized administrator of DigitalCommons@University of Nebraska - Lincoln. 


\title{
Comparison of the trivalent live attenuated vs. inactivated influenza vaccines among U.S. military service members
}

\author{
Angelia A. Eick ${ }^{\mathrm{a}, *}$, Zhong Wang ${ }^{\mathrm{a}}$, Hayley Hughes ${ }^{\mathrm{b}}$, Stephen M. Ford ${ }^{\mathrm{b}}$, Steven K. Tobler ${ }^{\mathrm{a}}$ \\ a Armed Forces Health Surveillance Center, U.S. Army Center for Health Promotion and Preventive Medicine, 2900 Linden Lane, \\ Suite 200, Silver Spring, MD 20910, USA \\ ${ }^{\mathrm{b}}$ Military Vaccine Agency, 5113 Leesburg Pike, Suite 402, Falls Church, VA 22041, USA
}

\section{A R T I C L E I N F O}

\section{Article history:}

Received 30 September 2008

Received in revised form 20 February 2009

Accepted 23 March 2009

Available online 19 April 2009

\section{Keywords:}

Influenza vaccine

Military

Effectiveness

\begin{abstract}
A B S T R A C T
Limited effectiveness data are available comparing live attenuated influenza vaccine (LAIV) to inactivated influenza vaccine (TIV) among adults. To compare the incidence of influenza-like illness following immunization of adults with LAIV vs. TIV, we conducted a retrospective cohort analysis of active component U.S. military personnel for the 2005-2006 and 2006-2007 influenza seasons. Recruits experienced a much higher burden of disease compared to non-recruits, with crude incidence rates of influenza-like illness 2-16 times higher than non-recruits depending on the season and cohort. For both seasons, a slightly greater protection from influenza-like illness was found for non-recruits who received TIV compared to LAIV (adjusted incidence rate ratio, 1.17 (95\% CI, 1.14-1.20) and 1.33 (95\% CI, 1.30-1.36), 2005-2006 and 2006-2007 influenza seasons, respectively). However, for Army and Air Force recruits, LAIV was found to provide significantly greater protection from influenza-like illnesses compared to TIV, with adjusted incidence rates of influenza-like illness $22-51 \%$ and $18-47 \%$ lower among LAIV compared to TIV recipients for the 2005-2006 and 2006-2007 influenza seasons, respectively. Possible reasons for differences in recruit and non-recruit findings include differences in pre-existing influenza antibody levels, differing respiratory disease burden, and/or unmeasured confounding. Consideration of these findings should be made when developing influenza immunization policies.
\end{abstract}

(C) 2009 Elsevier Ltd. All rights reserved.

\section{Introduction}

A live attenuated influenza vaccine (LAIV) has been licensed for use in children and adults in the U.S. since 2003. The vaccine, which is administered intranasally, represents the first new approach to influenza vaccines licensed since the development of split virus vaccines. The injectable trivalent, inactivated influenza vaccine (TIV) continues to be used regularly in the U.S. and remains the only option for groups not eligible to receive LAIV. Several studies have been conducted to evaluate the efficacy and effectiveness of LAIV in comparison to both people receiving TIV and unvaccinated individuals. However, the majority of these studies were conducted among children. In children less than 5 years of age and asthmatic children 6-17 years of age, LAIV was found to have superior efficacy and effectiveness in comparison to TIV [1-4]. A limited number of studies, mostly randomized trials or experimental challenge studies, have been conducted among adults. Although both vaccines have been shown to have absolute effectiveness against influenza-like illness in adults, studies directly

\footnotetext{
* Corresponding author. Tel.: +1 301319 3261; fax: +1 3013197620

E-mail address: angie.eick@us.army.mil (A.A. Eick).
}

comparing LAIV to TIV found mixed results on which vaccine had superior efficacy in the prevention of culture-confirmed influenza [5-9].

Within the U.S. military population, influenza and other respiratory infections have historically caused significant morbidity and mortality [10-13]. Recruit settings, service on ships, and other military settings which require crowding have been associated with outbreaks of influenza, occasionally despite high immunization rates [14-17]. The U.S. military has been a strong proponent for the development and use of influenza vaccines since the 1940s [10]. Annual influenza immunization for the active force began in the 1950s and total force (active and reserve components) influenza immunization remains a mandatory yearly requirement barring a contraindicating condition $[10,18]$. Continually since the 2003-2004 influenza season, military immunization policies have called for preferential use of LAIV for all eligible service members, with TIV reserved for those not eligible to receive LAIV [19-21]. Recommendations for preferential use of LAIV over TIV originated from greater demand for influenza vaccine during the 2003-2004 season and the need to maintain adequate supplies of TIV for high risk populations not eligible to receive LAIV [22,23] Although policies emphasize the use of LAIV, there have not been any investigations on the efficacy or effectiveness of this vaccine 
in comparison to TIV among military service members. The few population-based military studies that investigated influenza vaccine effectiveness were conducted among military basic trainees assessing TIV only during the 2003-2004 season and TIV and LAIV during the 2005-2006 season. These studies found very high vaccine effectiveness (92-94\%) against laboratory confirmed influenza $[24,25]$.

The U.S. military population provides a unique group to investigate and compare influenza vaccines, because it is primarily comprised of healthy adults who are annually immunized against influenza. In the general U.S. population, healthy young adults are not considered at high risk for significant influenza morbidity, so they are not targeted for immunization. As a result, this group has the lowest immunization rates compared to other age groups, making it difficult to investigate and compare influenza vaccines in this group outside of a clinical trial [26,27]. In order to evaluate how well LAIV and TIV protect against influenza-like illness (ILI) among the adult population and to better inform U.S. military influenza immunization policy, we conducted this analysis for the 2005-2006 and 2006-2007 influenza seasons.

\section{Materials and methods}

\subsection{Study design}

This was a retrospective cohort study. Two consecutive influenza seasons, 2005-2006 and 2006-2007, were investigated. The Defense Medical Surveillance System (DMSS) contains demographic, occupational, immunization, and medical encounter data for U.S. military service members [28]. Using DMSS, we identified the eligible cohorts for each year of the study. The cohorts consisted of service members in the active component of the U.S. Army, Air Force, Navy, or Marine Corps, who were stationed in the U.S. and who had documentation of receiving only one dose of either LAIV or TIV from 1 September to 30 April during the season of interest. Determination of which vaccine a service member receives is typically not dependant on self-selection, but driven by service specific policies and vaccine ordering, availability of vaccines (early in the season one vaccine type may be available before the other type or shortages could affect vaccine selection by the clinic), and pre-existing exclusions for one vaccine type (age, contraindicating illnesses). To ensure that our study population consisted of service members eligible to receive either vaccine, service members 50 years of age or older and those who were pregnant at the time of immunization were excluded from the cohort.

Person-time at risk was calculated by summing the time from 14 days after influenza immunization to the end of the surveillance period (30 April) or the occurrence of a right censoring event. Right censoring events included overseas deployment, termination of military service, or change in status from active to reserve or guard component. Affected individuals were not considered "at risk" for 30 days after each ILI; hence, the 30 days after each ILI was excluded from the person-time at risk.

\subsection{Identification of influenza-like illness}

DMSS was used to identify ILIs among the study cohorts. An ILI event was defined as an outpatient or inpatient medical visit which resulted in an ICD-9 diagnostic code (Table 1 ) consistent with an ILI. The ICD-9 codes selected for this study were previously shown to be associated with culture-confirmed influenza illnesses among the U.S. military population [29]. To be counted as an ILI event, the medical encounter had to occur during the follow-up period which began 14 days after immunization and ended on 30 April or the date of a right censoring event. Medical visits occur-
Table 1

ICD-9-CM codes used to identify influenza-like illness.

\begin{tabular}{ll}
\hline ICD-9-CM code & Description \\
\hline 79.99 & Viral infection, NOS a \\
382.9 & Otitis media, NOS a \\
460.0 & Nasopharyngitis, acute \\
461.9 & Acute sinusitis, unspecified \\
465.8 & Upper respiratory infection, other multiple sites \\
465.9 & Upper respiratory infection, acute NOS \\
466.0 & Bronchitis and bronchiolitis, acute \\
486.0 & Pneumonia, organism unspecified \\
487.0 & Influenza with pneumonia \\
487.1 & Influenza with other respiratory manifestations \\
487.8 & Influenza with other manifestations \\
490.0 & Bronchitis, not specified as acute or chronic \\
780.6 & Fever \\
786.2 & Cough \\
\hline
\end{tabular}

a NOS: not otherwise specified.

ring within 30 days of a primary visit were considered the same ILI event.

\subsection{Statistical analysis}

Three separate analytic plans were used for this study to address possible bias due to changing influenza activity during the season and timing of vaccine administration. The first method, the "Continuous Cohort", included the entire eligible cohort. People could enter the study cohort at any point during the influenza season when they received the influenza vaccine. The second method, the "November Cohort", included only people immunized during the month of November. For these first two methods, every new ILI event (30 days window applied) was counted as an outcome. The third method, the "Intense Cohort", included only people immunized from 1 September to 14 days prior to the start of the intense influenza period. Based on U.S. national data from the Centers for Disease Control and Prevention (CDC), the intense influenza period was defined as the 8 weeks with the highest percentage of isolates testing positive for influenza surrounding the peak influenza week (defined as the week with the highest percentage of tests positive for influenza) [30-32]. The intense influenza period was defined as 29 January 2006 through 01 April 2006 and 21 January 2007 through 24 March 2007 for the 2005-2006 and 2006-2007 influenza seasons, respectively. For the intense cohort, only the first ILI occurring during the intense influenza period was counted as an outcome. Person-time was censored on the date of the ILI medical visit.

For all analyses, recruits and non-recruits were analyzed separately due to differences in baseline risk of ILI and strong effect modification between recruit status and immunization received. Recruit status was defined at the time of immunization. In addition, recruits were stratified by service. Navy and Marine recruits were almost entirely immunized with TIV, therefore comparisons between the two vaccines could not be made in these populations. This was also seen for the Air Force recruit November cohort, which consisted mainly of LAIV recipients for the 2005-2006 influenza season and TIV recipients for the 2006-2007 season.

The incidence of ILI per 1000 person-years (PY) was calculated for people who received either LAIV or TIV. The crude incidence rate ratio (IRR) and 95\% confidence intervals (CI) were calculated comparing the ILI incidence in the LAIV group vs. the TIV group. In order to control for confounders, a Poisson regression model was used to estimate the adjusted IRR and 95\% CI. Confidence intervals that did not include 1.0 were considered statistically significant at an $\alpha=0.05$ level of significance. The model included covariates that were considered a prior to be risk factors for 
Table 2

Demographic and service characteristics of the non-recruit and recruit cohorts by season and immunization group.

\begin{tabular}{|c|c|c|c|c|c|c|c|c|}
\hline \multirow[t]{3}{*}{ Characteristic } & \multicolumn{4}{|c|}{ 2005-2006 influenza season } & \multicolumn{4}{|c|}{ 2006-2007 influenza season } \\
\hline & \multicolumn{2}{|c|}{ Non-recruits } & \multicolumn{2}{|l|}{ Recruits } & \multicolumn{2}{|c|}{ Non-recruits } & \multicolumn{2}{|l|}{ Recruits } \\
\hline & TIV & LAIV & TIV & LAIV & TIV & LAIV & TIV & LAIV \\
\hline Total cohort $(\mathrm{N})$ & $565,165(\%)$ & $136,588(\%)$ & $49,990(\%)$ & $20,335(\%)$ & $372,117(\%)$ & $384,974(\%)$ & $30,420(\%)$ & $17,547(\%)$ \\
\hline \multicolumn{9}{|l|}{ Age (years) } \\
\hline $17-19$ & 5.5 & 9.0 & 49.1 & 45.7 & 5.6 & 7.6 & 46.7 & 43.3 \\
\hline $20-29$ & 56.8 & 54.2 & 49.4 & 51.5 & 57.1 & 56.5 & 50.7 & 51.7 \\
\hline $30-39$ & 27.7 & 27.5 & 1.5 & 2.7 & 27.4 & 26.7 & 2.4 & 4.6 \\
\hline $40-49$ & 10.1 & 9.3 & $<0.1$ & $<0.1$ & 10.0 & 9.1 & 0.2 & 0.4 \\
\hline \multicolumn{9}{|l|}{ Sex } \\
\hline Male & 85.6 & 85.0 & 83.6 & 79.4 & 86.0 & 85.7 & 82.0 & 81.1 \\
\hline \multicolumn{9}{|l|}{ Race-ethnicity ${ }^{\mathrm{a}}$} \\
\hline White & 63.9 & 66.5 & 68.0 & 68.6 & 64.2 & 65.4 & 71.7 & 69.6 \\
\hline Black & 17.5 & 17.1 & 12.2 & 15.2 & 16.4 & 17.6 & 14.8 & 15.6 \\
\hline Hispanic & 9.8 & 8.8 & 10.0 & 9.6 & 10.1 & 9.2 & 6.6 & 9.1 \\
\hline Other/unknown & 8.9 & 7.7 & 9.9 & 6.7 & 9.5 & 7.8 & 7.0 & 5.8 \\
\hline \multicolumn{9}{|l|}{ Service } \\
\hline Army & 34.1 & 61.6 & 29.9 & 77.7 & 26.8 & 53.9 & 35.8 & 81.6 \\
\hline Air Force & 35.7 & 35.0 & 23.0 & 21.7 & 32.0 & 32.7 & 42.1 & 16.8 \\
\hline Marine Corps & 9.9 & 1.0 & 21.3 & 0.6 & 14.5 & 7.3 & 12.3 & 0.2 \\
\hline Navy & 20.3 & 2.4 & 25.8 & 0.0 & 26.8 & 6.1 & 9.8 & 1.4 \\
\hline \multicolumn{9}{|c|}{ Number of medical visits in previous year } \\
\hline 0 & 11.5 & 9.0 & 99.8 & 96.5 & 5.8 & 4.1 & 99.7 & 99.6 \\
\hline$<10$ & 66.9 & 68.3 & 0.2 & 3.5 & 50.3 & 48.5 & 0.4 & 0.4 \\
\hline $10-19$ & 15.2 & 16.0 & $<0.1$ & 0.0 & 26.2 & 28.4 & 0.0 & $<0.1$ \\
\hline $20+$ & 6.4 & 6.7 & 0.0 & 0.0 & 17.7 & 19.2 & 0.0 & $<0.1$ \\
\hline \multicolumn{9}{|l|}{ Ever hospitalized } \\
\hline Yes & 19.9 & 19.6 & $\mathrm{~N} / \mathrm{A}$ & $\mathrm{N} / \mathrm{A}$ & 19.2 & 19.2 & $\mathrm{~N} / \mathrm{A}$ & $\mathrm{N} / \mathrm{A}$ \\
\hline \multicolumn{9}{|c|}{ Other immunization on same day } \\
\hline Yes & 20.3 & 17.5 & 91.3 & 88.2 & 15.1 & 19.5 & 97.0 & 91.1 \\
\hline \multicolumn{9}{|c|}{ Other immunizations in previous $1-30$ days } \\
\hline Yes & 7.6 & 6.6 & 20.3 & 38.3 & 6.4 & 7.9 & 32.6 & 64.5 \\
\hline \multicolumn{9}{|c|}{ Flu vaccine given in previous influenza season } \\
\hline Yes & 45.6 & 50.4 & $\mathrm{~N} / \mathrm{A}$ & $\mathrm{N} / \mathrm{A}$ & 33.0 & 61.5 & $\mathrm{~N} / \mathrm{A}$ & $\mathrm{N} / \mathrm{A}$ \\
\hline
\end{tabular}

Percentages may not add up to $100 \%$ due to rounding. LAIV, live attenuated influenza vaccine; TIV, trivalent influenza vaccine.

a Race-ethnicity was self-reported and categorized in the DMSS. "Other" included Asian/Pacific Islander, American Indian/Alaska Native, and other.

influenza or vaccine selection and included sex, age at immunization, service component, race-ethnicity, region, number of medical visits in the past year, ever hospitalized (yes/no), influenza immunization during previous influenza season (yes/no), additional immunizations received on the same day as the influenza immunization (yes/no), and additional vaccines received 1-30 days prior to the influenza immunization (yes/no). Region was based on the location of the service member at the time of immunization. Regions were defined as New England (Connecticut, Maine, Massachusetts, New Hampshire, Vermont, Rhode Island), MidAtlantic (New Jersey, New York, Pennsylvania), East North Central (Illinois, Indiana, Michigan, Ohio, Wisconsin), West North Central (Iowa, Kansas, Minnesota, Missouri, Nebraska, North Dakota, South Dakota), South Atlantic (Delaware, Florida, Georgia, Maryland, North Carolina, South Carolina, Virginia, Washington, D.C., West Virginia), East South Central (Alabama, Kentucky, Mississippi, Tennessee), West South Central (Arkansas, Louisiana, Oklahoma, Texas), Mountain (Arizona, Colorado, Idaho, Montana, Nevada, New Mexico, Utah, Wyoming), and Pacific (Alaska, California, Hawaii, Oregon, Washington). In addition, for the non-recruits, separate analyses were conducted for each age category. SAS 9.1 (SAS Institute, Cary, NC, USA) was used for the analysis.

This investigation was conducted for military public health surveillance purposes and not research, therefore it did not undergo institutional review board examination. No external funding was received to conduct this investigation.

\section{Results}

\subsection{Study population}

For the 2005-2006 influenza season, we identified 701,753 non-recruits and 70,325 recruits. Among the non-recruits, 80.5\% received TIV and 19.5\% received LAIV. Among the recruits, 71.1\% and $28.9 \%$ received TIV and LAIV, respectively. Although the TIV and LAIV groups appear demographically similar for both the non-recruit and recruit populations, the population demographic differences were statistically significant (Table 2). This mainly reflects the large sample sizes of the populations and is not uncommon with studies of this size. However, of note, Soldiers made up the majority of the LAIV group for both recruits and non-recruits, where as the TIV group consisted of a similar percentage of Soldiers, Airmen, and Sailors. In addition, among the recruits, LAIV recipients were more likely to have had other immunizations administered in the 1-30 days prior to their influenza immunization.

For the 2006-2007 influenza season, the cohort consisted of 757,091 non-recruits and 47,967 recruits. TIV and LAIV immunizations were more evenly distributed for the 2006-2007 season with $49.2 \%$ and $63.4 \%$ of the non-recruits and recruits, respectively, receiving TIV. Consistent with the prior year, the LAIV group consisted of a high percentage of Soldiers, the TIV group was move evenly distributed with Soldiers, Airmen, Sailors and Marines, and recruits receiving LAIV were more likely to have received other immunizations in the 1-30 days prior to the influenza 
Table 3

Crude incidence rates of the non-recruit and recruit cohorts by demographic characteristics and immunization group, $2006-2007$.

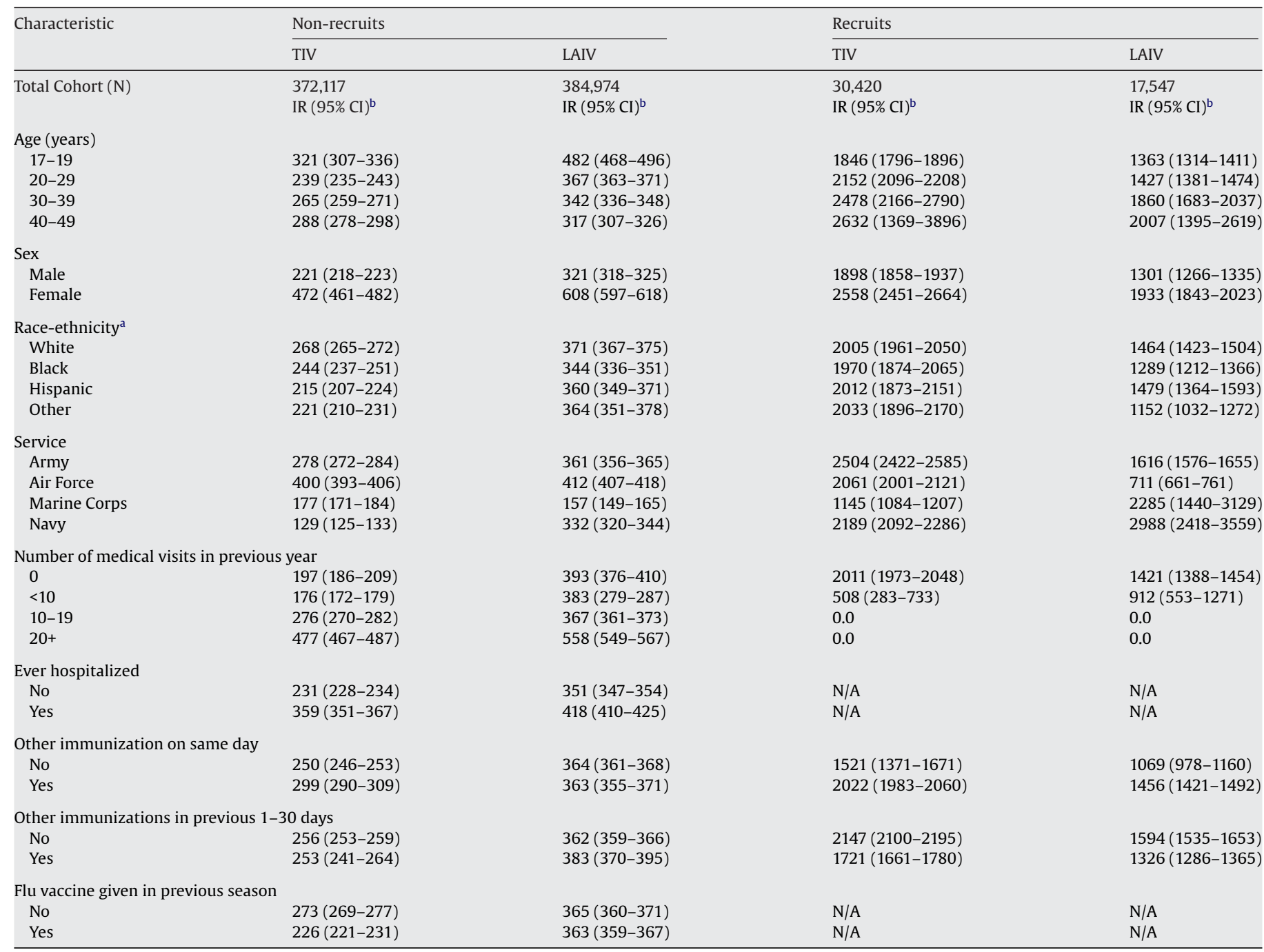

$\mathrm{IR}=$ incidence rate; $\mathrm{CI}$ = confidence intervals; LAIV = live attenuated influenza vaccine; TIV = trivalent influenza vaccine.

a Race-ethnicity was self-reported and categorized in the DMSS. "Other" included Asian/Pacific Islander, American Indian/Alaska Native, and other.

b Crude incidence rate per 1000 person-years.

immunization (Table 2). In addition, non-recruit LAIV recipients were more likely than TIV recipients to have been vaccinated for influenza during the previous influenza season.

\subsection{ILI incidence}

The crude incidence of ILIs stratified by various demographic and service characteristics for the 2006-2007 influenza season is presented in Table 3. Overall, crude ILI incidence rates were 5-9 times higher and 2-16 times higher comparing recruits to non-recruits for TIV recipients and LAIV recipients, respectively. Females consistently had higher crude rates than males. Among non-recruits, Airmen had the highest crude rates compared to the other services regardless of vaccine group. Similar distributions were seen for the 2005-2006 season (Supplemental Table 1).

The timing of LAIV and TIV immunizations, distribution of ILI events, distribution of CDC influenza confirmed specimens, and distribution of censoring events for the continuous cohort for both seasons are presented in Fig. 1 [31,32]. For the non-recruits, the majority of influenza immunizations occurred by the end of December for both season. Since recruits were continuously entering service throughout the influenza season, recruit immunizations were more evenly distributed throughout each season. For both seasons, peak ILI activity occurred during the first 2 months of the new year, although the 2006 season did have a slightly lower peak during November and December. Censoring events for the both the recruits and non-recruits were relatively evenly distributed through each season.

\subsubsection{Non-recruits}

For the 2005-2006 continuous and November cohorts, the ILI incidence per 1000 PY was 358.7 and 361.3 among LAIV recipients and 271.6 and 291.5 for TIV recipients, respectively. For the intense cohort, the ILI incidence was higher at 407.5 per 1000 PY and 315.2 per 1000 PY for LAIV and TIV immunized, respectively. Regardless of the cohort, the ILI incidence among LAIV recipients was higher than TIV recipients, with an adjusted IRR and 95\% CI of 1.17 (1.14-1.20) (Table 4).

Incidence rates for the 2006-2007 influenza season were similar to rates for the 2005-2006 season, however the magnitude of the IRRs was greater (Table 4). The ILI incidence among LAIV recipients was higher than TIV recipients for all three analysis cohorts for the 2006-2007 influenza season (adjusted IRR [95\% CI]: 1.25 $(1.23-1.27)$ to $1.33(1.30-1.36))$. 

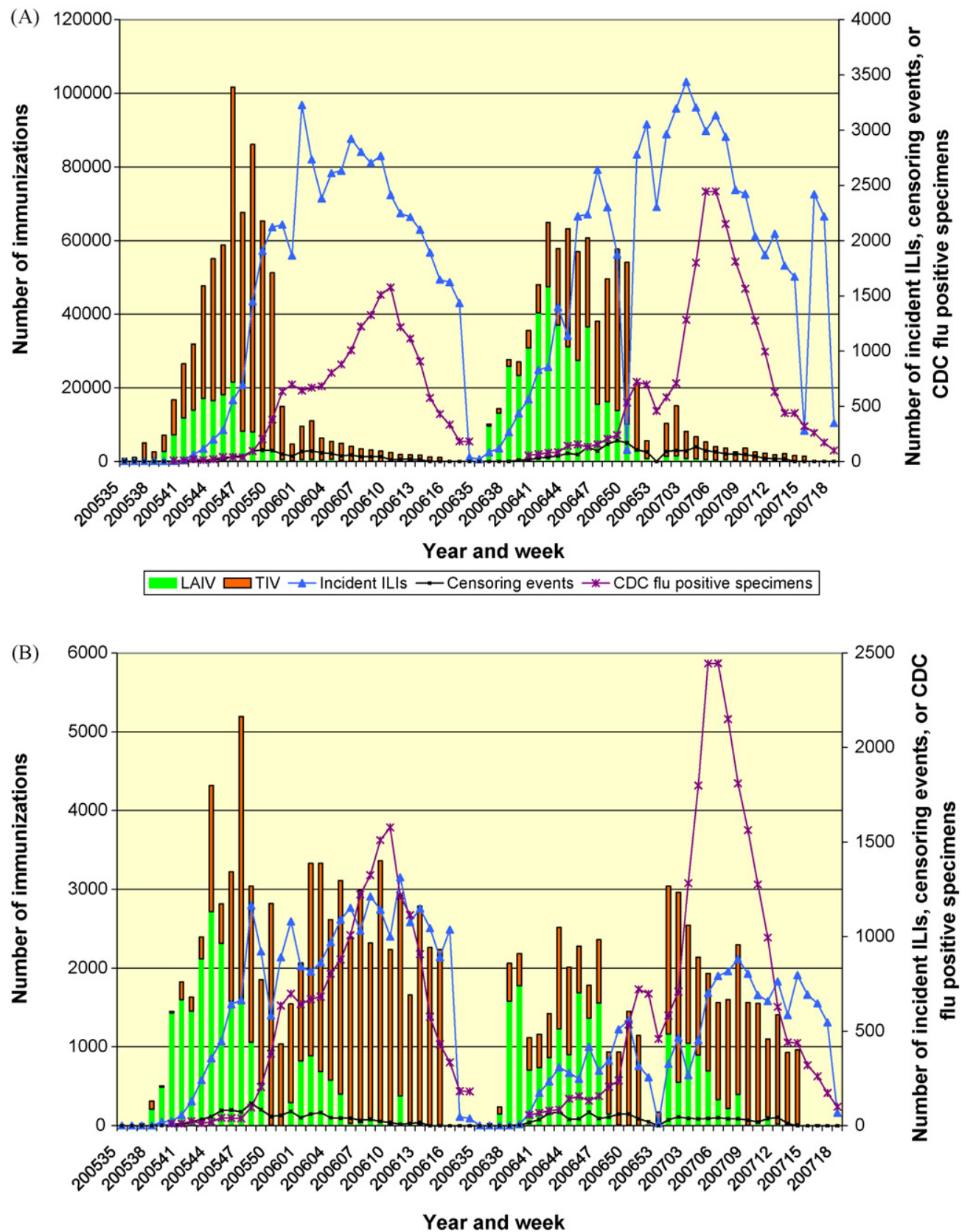

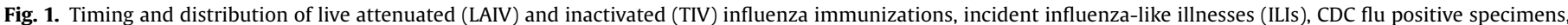
and censoring events for non-recruits (A) and recruits (B) for the 2005-2006 and 2006-2007 influenza seasons.

For the age stratified analysis, IRRs decreased with increasing age category. The highest IRRs were in the 17-19-year-old age category and lowest IRRs were in the 40-49-year-old age category for both seasons and for all cohorts (Supplemental Table 2).

\subsubsection{Recruits}

Table 5 combines the results of the 2005-2006 and 2006-2007 influenza seasons for the Army and Air Force recruits. Unlike the non-recruit population, recruit LAIV recipients had statistically significantly lower ILI incidence rates than TIV recipients. This finding was consistent for both seasons and services and all cohorts (where sample size was sufficient to perform calculations) except for the 2006-2007 Air Force intense cohort, which did not reach statistical significance (IRR and 95\% CI: $0.82(0.62-1.09)$ ). LAIV recipients had a relative reduction in adjusted ILI incidence of $22-51 \%$ and $18-47 \%$ compared to TIV recipients for the 2005-2006 and 2006-2007 seasons, respectively.

\section{Discussion}

Over two consecutive influenza seasons, we were able to follow large cohorts of service members to assess how well LAIV and TIV protected against ILI. Our findings of greater protection from ILI with LAIV compared to TIV for recruits and slightly greater protection with TIV compared to LAIV for non-recruits were initially surprising. However, after consideration of these results we hypothesize that several factors may be contributing to this difference.

Among the recruit population, for both influenza seasons, we found a significant protective effect of LAIV against ILI compared to TIV recipients. Two possible explanations for these finding are 
Table 4

Crude and adjusted incidence rate ratios comparing LAIV to TIV among non-recruits by analytical cohort and influenza season.

\begin{tabular}{|c|c|c|c|c|c|c|}
\hline \multirow[t]{2}{*}{ Analysis cohort } & \multicolumn{3}{|c|}{ 2005-2006 Influenza season } & \multicolumn{3}{|c|}{ 2006-2007 Influenza season } \\
\hline & $\begin{array}{l}\text { ILI incidence } \\
\text { rate (per } 1000 \\
\text { person-years) }\end{array}$ & $\begin{array}{l}\text { Crude } \\
\text { incidence rate } \\
\text { ratio }(95 \% \mathrm{CI}) \\
\text { LAIV vs. TIV }\end{array}$ & $\begin{array}{l}\text { Adjusted } \\
\text { incidence rate } \\
\text { ratio }(95 \% \mathrm{CI})^{\mathrm{a}} \\
\text { LAIV vs. TIV }\end{array}$ & $\begin{array}{l}\text { ILI incidence } \\
\text { rate (per } 1000 \\
\text { person-years) }\end{array}$ & $\begin{array}{l}\text { Crude } \\
\text { incidence rate } \\
\text { ratio }(95 \% \mathrm{CI}) \\
\text { LAIV vs. TIV }\end{array}$ & $\begin{array}{l}\text { Adjusted } \\
\text { incidence rate } \\
\text { ratio }(95 \% \mathrm{CI})^{\mathrm{a}} \\
\text { LAIV vs. TIV }\end{array}$ \\
\hline \multicolumn{7}{|l|}{ Continuous cohort } \\
\hline LAIV recipients & 358.7 & $1.32(1.30-1.34)$ & $1.17(1.15-1.18)$ & 363.8 & $1.42(1.40-1.44)$ & $1.25(1.23-1.27)$ \\
\hline TIV recipients & 271.6 & - & - & 255.7 & - & - \\
\hline \multicolumn{7}{|l|}{ November cohort } \\
\hline LAIV recipients & 361.3 & $1.24(1.21-1.27)$ & $1.17(1.14-1.20)$ & 353.1 & $1.44(1.41-1.48)$ & $1.28(1.24-1.31)$ \\
\hline TIV recipients & 291.5 & - & - & 244.9 & - & - \\
\hline \multicolumn{7}{|l|}{ Intense cohort } \\
\hline LAIV recipients & 407.5 & $1.29(1.26-1.33)$ & $1.17(1.14-1.20)$ & 455.4 & $1.49(1.47-1.53)$ & $1.33(1.30-1.36)$ \\
\hline TIV recipients & 315.2 & - & - & 305.4 & - & - \\
\hline
\end{tabular}

ILI, influenza-like illness; LAIV, live attenuated influenza vaccine; TIV, trivalent influenza vaccine; CI, confidence intervals.

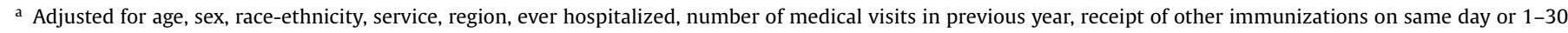
days prior to influenza immunization, and receipt of influenza immunization in previous influenza season.

that the recruit population has an intense burden of respiratory disease compared to non-recruits and recruits may also have a different immune response to immunization compared to routinely immunized non-recruits. Our recruit findings were similar to what has been shown for studies comparing the vaccines in children. Belshe et al. found a $54.9 \%$ reduction in the number of cultureconfirmed influenza cases among children 6-59 months for LAIV compared to TIV recipients [1]. This effect is larger, but still similar to our finding of approximately a $22-51 \%$ reduction in ILIs among recruits. Although the recruit population is made up of people $17-42$ years old, the majority of recruits (60-65\%) were 20 years of age or younger. This age group falls into the category with the lowest immunization rates in the United States, mostly likely because they were not persons for whom annual immunization was recommended $[26,27]$. We suspect that the majority of recruits were not immunized against influenza in the years prior to joining the service and not at high risk for severe complications of influenza disease. This may lead to some recruits having an immune system that is relatively naive to influenza and to have a different immune response compared to that of a more seasoned service member who has received multiple annual influenza immunizations. Previous studies have found LAIV to elicit a more robust immune response and increased viral replication in unprimed subjects [33-36]. These findings may explain the higher protection of LAIV compared to TIV in recruits. With the new 2008 recommendation for annual influenza immunization of children 5-18 years of age by the Advisory Committee on Immunization Practices, it will be important to assess if prior immunization rates among recruits are increasing and whether these increases effect the robust ILI protection we observed with LAIV [37].

Table 5

Crude and adjusted incidence rate ratios comparing LAIV and TIV among recruits by service and analytical cohort: 2005-2006 and 2006-2007 influenza seasons.

\begin{tabular}{|c|c|c|c|c|c|c|}
\hline \multirow[t]{2}{*}{ Analysis cohort } & $\begin{array}{l}\text { ILI incidence } \\
\text { rate (per } 1000 \\
\text { person-years) }\end{array}$ & $\begin{array}{l}\text { Crude } \\
\text { incidence rate } \\
\text { ratio }(95 \% \mathrm{CI}) \\
\text { LAIV vs. TIV } \\
\end{array}$ & $\begin{array}{l}\text { Adjusted } \\
\text { incidence rate } \\
\text { ratio }(95 \% \mathrm{CI})^{\mathrm{a}} \\
\text { LAIV vs. TIV } \\
\end{array}$ & $\begin{array}{l}\text { ILI incidence } \\
\text { rate (per } 1000 \\
\text { person-years) }\end{array}$ & $\begin{array}{l}\text { Crude } \\
\text { incidence rate } \\
\text { ratio }(95 \% \mathrm{CI}) \\
\text { LAIV vs. TIV }\end{array}$ & $\begin{array}{l}\text { Adjusted } \\
\text { incidence rate } \\
\text { ratio }(95 \% \mathrm{CI})^{\mathrm{a}} \\
\text { LAIV vs. TIV }\end{array}$ \\
\hline & \multicolumn{3}{|l|}{ Army } & \multicolumn{3}{|l|}{ Air force } \\
\hline \multicolumn{7}{|l|}{ 2005-2006 Season } \\
\hline $\begin{array}{l}\text { LAIV recipients } \\
\text { TIV recipients }\end{array}$ & $\begin{array}{l}1458.7 \\
2735.2\end{array}$ & $0.53(0.52-0.55)$ & $0.53(0.51-0.55)$ & $\begin{array}{l}1310.8 \\
2325.9\end{array}$ & $0.56(0.54-0.59)$ & $0.64(0.59-0.69)$ \\
\hline $\begin{array}{l}\text { November cohort } \\
\text { LAIV recipients } \\
\text { TIV recipients }\end{array}$ & $\begin{array}{l}1326.2 \\
1406.0\end{array}$ & $0.94(0.87-1.03)$ & $0.78(0.71-0.87)$ & $\begin{array}{l}\text { Not applicable - counts } \\
\text { too small }\end{array}$ & & \\
\hline $\begin{array}{l}\text { Intense cohort } \\
\text { LAIV recipients } \\
\text { TIV recipients }\end{array}$ & $\begin{array}{l}1736.5 \\
2158.7\end{array}$ & $0.80(0.74-0.88)$ & $0.74(0.67-0.81)$ & $\begin{array}{l}701.7 \\
2073.4\end{array}$ & $0.34(0.30-0.39)$ & $0.49(0.41-0.59)$ \\
\hline \multicolumn{7}{|l|}{ 2006-2007 Season } \\
\hline $\begin{array}{l}\text { LAIV recipients } \\
\text { TIV recipients }\end{array}$ & $\begin{array}{r}1615.7 \\
2503.8\end{array}$ & $0.65(0.62-0.67)$ & $0.66(0.63-0.69)$ & $\begin{array}{l}711.2 \\
2061.1\end{array}$ & $0.35(0.32-0.37)$ & $0.53(0.47-0.60)$ \\
\hline $\begin{array}{l}\text { November cohort } \\
\text { AIV recipients } \\
\text { TIV recipients }\end{array}$ & $\begin{array}{l}1668.2 \\
2594.6\end{array}$ & $0.64(0.58-0.71)$ & $0.73(0.60-0.89)$ & $\begin{array}{l}\text { Not applicable - counts } \\
\text { too small }\end{array}$ & & \\
\hline $\begin{array}{l}\text { Intense cohort } \\
\text { LAIV recipients } \\
\text { TIV recipients }\end{array}$ & $\begin{array}{l}2004.3 \\
2810.0\end{array}$ & $0.71(0.61-0.83)$ & $0.71(0.58-0.86)$ & $\begin{array}{l}845.9 \\
1072.3\end{array}$ & $0.79(0.69-0.90)$ & $0.82(0.62-1.09)$ \\
\hline
\end{tabular}

LAIV, live attenuated influenza vaccine; TIV, trivalent influenza vaccine; ILI, influenza-like illness; CI, confidence intervals.

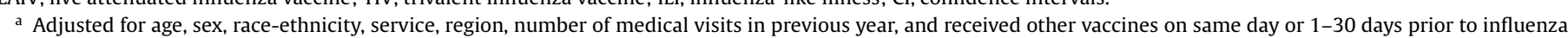
vaccine. 
The intense burden of respiratory disease found in the recruit setting may also play a role in the differences between recruits and non-recruits. Crowded living conditions, stressful environments, and the continuous entry of people from throughout the United States into this population make this setting ideal for the spread of respiratory pathogens $[38,39]$. Not surprisingly, we found rates of ILIs to be $2-16$ times higher among the recruits compared to the non-recruits depending on the service, immunization group, analysis cohort, and year of study. Previous studies of the recruit population have reported significant burden of respiratory disease and outbreaks of disease, due primarily to adenovirus, influenza, respiratory syncytial virus, and bacterial infections [14,18,40-43]. The high burden and mixing of a variety of respiratory pathogens in this setting may alter the protective effect of vaccines. If influenza plays a role in subsequent viral or bacterial infections, then increased protection by LAIV may appear even greater in this recruit setting. In addition, the broad case definition of ILI may encompass these other acute respiratory pathogens.

The lower incidence of ILIs among non-recruit TIV recipients compared to LAIV recipients was similar to most reports among the general U.S. adult population. In a randomized, placebo-controlled challenge study, Treanor et al. reported a higher protective efficacy of LAIV (85\%) compared to TIV (71\%) among adults but this difference lacked statistical significance [6]. However, Nichol et al. found LAIV to be statistically significantly effective at preventing severe febrile illnesses and febrile upper respiratory tract illnesses compared to placebo [8]. Another randomized, placebo-controlled trial by Ohmit et al., found a higher absolute efficacy for TIV for culture or real-time PCR positive influenza (75\% and $16 \%$ ) compared to LAIV (48\% and 8\%) for both the 2004-2005 and 2005-2006 influenza seasons among adults, but with overlapping confidence intervals [5,7]. TIV has also been reported by Bridges et al. to be $86 \%$ efficacious against laboratory confirmed influenza when compared to placebo [9]. Although our findings are consistent with these previous studies in adults, we were able to show statistically significant differences at an $\alpha=0.05$ level between LAIV and TIV protection from ILI. One possible explanation for this finding in our non-recruit population is high annual influenza immunization rates. Pre-existing antibody from multiple years of influenza immunizations may be playing a role in reducing the replication and antibody response to LAIV [33,34,36,44-47]. However, our findings of an inverse relationship between LAIV to TIV IRRs and age, as shown in (supplemental Table 2), is counter to the hypothesis that older age groups would have received more influenza immunizations and therefore have greater interference of pre-existing antibody with LAIV. One explanation of this finding is that older age may not directly correlate with more years in military service or more influenza immunizations. However, we feel these findings really point out that the interaction between LAIV and the immune system is multifaceted and requires more detailed investigations of the innate and adaptive immune responses to influenza immunizations.

An additional issue that could be playing a role in the difference between recruit and non-recruit findings may be differences in circulating influenza strains. Although we did not have data to specifically identify which strains were circulating in our populations, a previous study has reported differing vaccine effectiveness for LAIV and TIV when looking at influenza A and B viruses separately. The study by Ohmit et al., although under-powered for the strain specific assessment, reported a reduced protection of LAIV against influenza B viruses [5]. Although influenza B viruses were the minority, based on CDC data, they were present during both seasons, typically later in the season $[29,30]$. If non-recruits were more likely to be exposed to influenza $B$ viruses than recruits, then it may partially explain the differences we saw with LAIV.

The data used for this investigation present several limitations. The principal limitation is our use of ICD-9 codes consistent with
ILI for the outcome of interest instead of laboratory confirmed influenza illness. By using this less specific case definition, it is likely some of the events were caused by viral or bacterial respiratory pathogens other than influenza, and we overestimated the true incidence of influenza. However, to minimize this risk, we chose to use ICD-9 codes that had previously been shown in a very similar population to be most associated with culture-confirmed influenza cases [29]. A benefit of this methodology is that it allows for assessment of the vaccines on a large population scale which would be infeasible for a culture-confirmed study. Additional weaknesses include a lack of smoking status, lack of knowledge about the number of children in the household, and lack of medical and immunization data prior to entry into military service. We were unable to determine whether recruits were immunized or infected with influenza in the year prior to entry into the service or to control for potential confounders such as past medical history or medical care usage patterns. However, in order to enter military service, applicants must meet certain physical and medical eligibility standards, which should decrease the likelihood of inclusion of recruits with significant medical conditions that would put them at higher risk for ILI $[48,49]$. Selection bias may have occurred for the November cohort, but was necessary to be able to control for differences in the timing of LAIV and TIV administration. Using the CDC national influenza data to determine the windows for the intense cohorts may not accurately account for region and military differences in peak influenza activity. Although military specific data were not available, we did determine region specific windows for peak influenza activity using the CDC regional data and performed regional intense cohort analyses. The findings from these regional analyses were similar to the overall intense cohorts presented here (data not shown). The possibility for residual confounding and/or unmeasured confounding is also a limitation to the study.

Our results support continued immunization and preferential use of LAIV for the recruit population. Among adults regularly immunized against influenza and in a non-recruit setting, our findings of a slightly higher effectiveness with TIV favor immunization with this vaccine. Consideration of these findings should be made when developing influenza immunization policies. This study was strengthened by the consistency of findings using multiple study cohorts and over multiple influenza seasons. Additional studies of this nature are needed among adults to see if these findings are generalizable to the general U.S. population. In addition, investigation of the role of annual influenza immunizations in the adult population on the immunogenicity and viral replication of LAIV are needed. Continued assessment of these vaccines in subsequent influenza seasons is essential, especially during years of sub-optimal vaccine strain match and more significant seasons to assess how well these vaccines perform.

\section{Acknowledgements}

We would like to recognize Dr. Michael S. Bloom, Dr. John F. Brundage, and Dr. Jean A. Roayaei from the Armed Forces Health Surveillance Center for their advice on study methods and review of the manuscript.

\section{Appendix A. Supplementary data}

Supplementary data associated with this article can be found, in the online version, at doi:10.1016/j.vaccine.2009.03.088.

\section{References}

[1] Belshe RB, Edwards KM, Vesikari T, Black SV, Walker RE, Hultquist M, et al. Live attenuated versus inactivated influenza vaccine in infants and young children. N Engl J Med 2007;356:685-96. 
[2] Shuler CM, Iwamoto M, Bridges CB, Marin M, Neeman R, Gargiullo P, et al. Vaccine effectiveness against medically attended, laboratory-confirmed influenza among children aged 6 to 59 months, 2003-2004. Pediatrics 2007:119:e587-95.

[3] Allison MA, Daley MF, Crane LA, Barrow J, Beaty BL, Allred N, et al. Influenza vaccine effectiveness in healthy 6- to 21-month-old children during the 2003-2004 season. J Pediatr 2006;149:755-62.

[4] Fleming DM, Crovari P, Wahn U, Klemola T, Schlesinger Y, Langussis A, et al. Comparison of the efficacy and safety of live attenuated cold-adapted influenza vaccine, trivalent, with trivalent inactivated influenza virus vaccine in children and adolescents with asthma. Pediatr Infect Dis J 2006;25:860-9.

[5] Ohmit SE, Victor JC, Rotthoff JR, Teich ER, Truscon RK, Baum LL, et al. Prevention of antigenically drifted influenza by inactivated and live attenuated vaccines. N Engl J Med 2006;355:2513-22.

[6] Treanor JJ, Kotloff K, Betts RF, Belshe R, Newman F, Iacuzio D, et al. Evaluation of trivalent, live, cold-adapted (CAIV-T) and inactivated (TIV) influenza vaccines in prevention of virus infection and illness following challenge of adults with wild-type influenza A (H1N1), A (H3N2), and B viruses. Vaccine 1999;18: 899-906.

[7] Ohmit SE, Victor JC, Teich ER, Truscon RK, Rotthoff JR, Newton DW, et al. Prevention of symptomatic seasonal influenza in 2005-2006 by inactivated and live attenuated vaccines. J Infect Dis 2008;198:312-7.

[8] Nichol KL, Mendelman PM, Mallon KP, Jackson LA, Gorse GJ, Belshe RB, et al. Effectiveness of live, attenuated intranasal influenza virus vaccine in healthy, working adults: a randomized controlled trial. JAMA 1999;282:137-44.

[9] Bridges CB, Thompson WW, Meltzer MI, Reeve GR, Talamonti WJ, Cox NJ, et al. Effectiveness and cost-benefit of influenza vaccination of healthy working adults: a randomized controlled trial. JAMA 2000;284:1655-63.

[10] Grabenstein JD, Pittman PR, Greenwood JT, Engler RJ. Immunization to Protect the US Armed Forces: heritage, current practice, and prospects. Epidemiol Rev 2006;28:3-26.

[11] Sencer DJ, Millar JD. Reflections on the 1976 swine flu vaccination program. Emerg Infect Dis 2006;12:29-33.

[12] Gaydos JC, Hodder RA, Top Jr FH, Soden VJ, Allen RG, Bartley JD, et al. Swine influenza A at Fort Dix, New Jersey (January-February 1976). I. Case finding and clinical study of cases. J Infect Dis 1977;136(Suppl. S356-62)

[13] Hodder RA, Gaydos JC, Allen RG, Top Jr FH, Nowosiwsky T, Russell PK. Swine influenza A at Fort Dix, New Jersey (January-February 1976). III. Extent of spread and duration of the outbreak. J Infect Dis 1977;136(Suppl. S369-75).

[14] McNeill KM, Vaughn BL, Brundage MB, Li Y, Poropatich RK, Gaydos JC. Clinical presentations for influenza and influenza-like illness in young, immunized soldiers. Mil Med 2005;170:94-7.

[15] Earhart KC, Beadle C, Miller LK, Pruss MW, Gray GC, Ledbetter EK, et al. Outbreak of influenza in highly vaccinated crew of U.S. Navy ship. Emerg Infect Dis 2001;7:463-5.

[16] Laurel VL, De Witt CC, Geddie YA, Yip MC, Dolan DM, Canas LC, et al. An outbreak of influenza A caused by imported virus in the United States, July 1999. Clin Infect Dis 2001;32:1639-42.

[17] Ksiazek TG, Olson JG, Irving GS, Settle CS, White R, Petrusso R. An influenza outbreak due to A/USSR/77-like (H1N1) virus aboard a US Navy ship. Am J Epidemiol 1980;112:487-94.

[18] Gray GC, Callahan JD, Hawksworth AW, Fisher CA, Gaydos JC. Respiratory diseases among U.S. military personnel: countering emerging threats. Emerg Infect Dis 1999;5:379-85.

[19] Department of the Army, Headquarters, United States Army Medical Command. OPERATIONS ORDER 08-67 (2008-2009 Influenza Vaccine Immunization Program), 2008 [Accessed at http://www.vaccines.mil/documents/ 1211flu_OPERATIONS_ORDER_08_67_2008-2009.pdf on 20 February 2009].

[20] Department of the Air Force, Headquarters United States Air Force. Air Force 2008-2009 Influenza Immunization Program Guidance, 2008. [Accessed at http://www.vaccines.mil/documents/1209AF\%20Influenza\%20Guidance\% 2008-09.pdf on 20 February 2009].

[21] BUMED Washington DC. Policy for the Use of Influenza Vaccine for 2008-2009, 2008. [Accessed at http://www.vaccines.mil/documents/ 1210BUMED_influenza_0809.pdf on 20 February 2009].

[22] United States Army Medical and Material Agency. 2003-2004 Influenza Virus Vaccine (Flu)/Update/Change/Management of Influenza Vaccine; 2003. [Accessed at http://usamma.detrick.army.mil/ftp/mmqc_messages/I044001. txt on 20 February 2009].

[23] United States Army Medical and Material Agency. Flumist/Influenza Vaccine/Information Bulletin; 2005. [Accessed at http://usamma.detrick.army.mil/ $\mathrm{ftp} / \mathrm{mmqc}$ messages/Q051233.txt on 20 February 2009].

[24] Russell KL, Ryan MA, Hawksworth A, Freed NE, Irvine M, Daum LT, et al. Effectiveness of the 2003-2004 influenza vaccine among U.S. military basic trainees: a year of suboptimal match between vaccine and circulating strain. Vaccine 2005;23:1981-5.

[25] Strickler JK, Hawksworth AW, Myers C, Irvine M, Ryan MA, Russell KL. Influenza vaccine effectiveness among US military basic trainees, 2005-06 season. Emerg Infect Dis 2007;13:617-9.
[26] Centers for Disease Control and Prevention. Estimates of Influenza Vaccination Target Population Sizes in 2006 and Recent Vaccine Uptake Levels; 2006. [Accessed at www.cdc.gov/flu/professionals/vaccination/pdf/targetpopchart. pdf on 20 February 2009].

[27] Centers for Disease Control and Prevention. Self-reported influenza vaccination coverage trends 1989-2005 among adults by age group, risk group, race/ethnicity, health-care worker status, and pregnancy, United States, National Health Interview Survey (NHIS), 2007. [Accessed at www.cdc.gov/flu/ professionals/vaccination/pdf/vaccinetrend.pdf on 20 February 2009].

[28] Rubertone MV, Brundage JF. The Defense Medical Surveillance System and the Department of Defense serum repository: glimpses of the future of public health surveillance. Am J Public Health 2002;92:1900-4.

[29] Marsden-Haug N, Foster VB, Gould PL, Elbert E, Wang H, Pavlin JA. Code-based syndromic surveillance for influenza like illness by International Classification of Diseases, Ninth revision. Emerg Infect Dis 2007;13:207-16.

[30] King Jr JC, Stoddard JJ, Gaglani MJ, Moore KA, Magder L, McClure E, et al. Effectiveness of school-based influenza vaccination. $\mathrm{N}$ Engl J Med 2006;355:2523-32.

[31] Centers for Disease Control and Prevention. 2005-2006 U.S. Influenza Season Summary, 2006. [Accessed at http://www.cdc.gov/flu/weekly/ weeklyarchives2005-2006/05-06summary.htm on 20 February 2009].

[32] Centers for Disease Control and Prevention (CDC). Weekly Report: Influenza Summary Update, Week ending May 19, 2007-Week 20, 2007. [Accessed at http://www.cdc.gov/flu/weekly/weeklyarchives2006-2007/weekly20.htm on 20 February 2009].

[33] Cox NJ, Bridges CB. Inactivated and live attenuated influenza vaccines in young children-how do they compare? N Engl J Med 2007;356:729-31.

[34] Sasaki S, Jaimes MC, Holmes TH, Dekker CL, Mahmood K, Kemble GW, et al. Comparison of the influenza virus-specific effector and memory B-cell responses to immunization of children and adults with live attenuated or inactivated influenza virus vaccines. J Virol 2007;81:215-28.

[35] Lee MS, Mahmood K, Adhikary L, August MJ, Cordova J, Cho I, et al. Measuring antibody responses to a live attenuated influenza vaccine in children. Pediatr Infect Dis J 2004;23:852-6.

[36] Cox RJ, Brokstad KA, Ogra P. Influenza virus: immunity and vaccination strategies. Comparison of the immune response to inactivated and live, attenuated influenza vaccines. Scand J Immunol 2004;59:1-15.

[37] Fiore AE, Shay DK, Broder K, Iskander JK, Uyeki TM, Mootrey G, et al. Prevention and control of influenza: recommendations of the Advisory Committee on Immunization Practices (ACIP), 2008. MMWR Recomm Rep 2008;57:1-60.

[38] Lee T, Jordan NN, Sanchez JL, Gaydos JC. Selected nonvaccine interventions to prevent infectious acute respiratory disease. Am J Prev Med 2005;28:305-16.

[39] Gray GC, Mitchell BS, Tueller JE, Cross ER, Amundson DE. Pneumonia hospitalizations in the US Navy and Marine Corps: rates and risk factors for 6,522 admissions, 1981-1991. Am J Epidemiol 1994;139:793-802.

[40] Brundage JF, Gunzenhauser JD, Longfield JN, Rubertone MV, Ludwig SL, Rubin FA, et al. Epidemiology and control of acute respiratory diseases with emphasis on group A beta-hemolytic streptococcus: a decade of U.S. Army experience. Pediatrics 1996;97:964-70.

[41] Balicer RD, Huerta M, Levy Y, Davidovitch N, Grotto I. Influenza outbreak control in confined settings. Emerg Infect Dis 2005;11:579-83.

[42] O'Shea MK, Ryan MA, Hawksworth AW, Alsip BJ, Gray GC. Symptomatic respiratory syncytial virus infection in previously healthy young adults living in a crowded military environment. Clin Infect Dis 2005;41:311-7.

[43] Russell KL, Hawksworth AW, Ryan MA, Strickler J, Irvine M, Hansen CJ, et al. Vaccine-preventable adenoviral respiratory illness in US military recruits, 1999-2004. Vaccine 2006;24:2835-42.

[44] Bernstein DI, Yan L, Treanor J, Mendelman PM, Belshe R. Cold-Adapted, Trivalent, Influenza Vaccine Study Group. Effect of yearly vaccinations with live, attenuated, cold-adapted, trivalent, intranasal influenza vaccines on antibody responses in children. Pediatr Infect Dis J 2003;22:28-34

[45] Buonagurio DA, O'Neill RE, Shutyak L, D'Arco GA, Bechert TM, Kazachkov Y et al. Genetic and phenotypic stability of cold-adapted influenza viruses in a trivalent vaccine administered to children in a day care setting. Virology 2006;347:296-306

[46] He XS, Holmes TH, Zhang C, Mahmood K, Kemble GW, Lewis DB, et al. Cellular immune responses in children and adults receiving inactivated or live attenuated influenza vaccines. J Virol 2006;80:11756-66.

[47] Sasaki S, He XS, Holmes TH, Dekker CL, Kemble GW, Arvin AM, et al. Influence of prior influenza vaccination on antibody and B-cell responses. PLoS ONE 2008;3:e2975.

[48] Department of Army, Headquarters. Army Regulation 40-501, 2002. Accessed at https://www.jagcnet.army.mil/JAGCNetInternet/Homepages/AC/NewJARO. nsf/(JAGCNetDocID)/C3219854E28FF5FA852571BF0063076C/\$FILE/AR + 40$501+20020930$.pdf on 20 February 2009 .

[49] Department of Defense, Headquarters, United States Military Entrance Processing Command. US MEPCOM Regulation No. 40-1, 2002. [Accessed at http://www.mepcom.army.mil/publications/pdf/regs/r-0040-001.pdf on 20 February 2009]. 